\title{
Play, Rewind, Play Again: Experiences of Millennials' Usage of the Cassette Tape as Music Media
}

\author{
Waleed Rashidi \\ California State University, Fullerton
}

This paper was presented at the 2018 International Summit of the

Music \& Entertainment Industry Educators Association

March 22-24, 2018

https://doi.org/10.25101/18.23

\section{Abstract}

Cassette tape purchases in the United States increased $35 \%$ from 2016 to 2017, with 174,000 units sold in 2017 (Caulfield 2018). New titles from contemporary artists and reissues of classic albums are currently being released on cassette, with teens and young adults as some of the recent users of the analog technology.

This exploratory qualitative study's purpose is to describe and categorize the experiences of millennials' recent purchases and playing of cassette tapes via a presentation of themes derived from multiple in-depth interviews. The study offers insight on how some millennials purchase cassettes, where and how they play their cassettes, and the attractive qualities of engaging with a format that may have been viewed as commercially obsolete.

In-depth telephone and in-person interviews with eighteen qualifying participants were conducted from February to June 2018. Participant requirements include those born between 1983 to 1999 , who purchased and played at least one cassette tape in the last two years. Interview responses were audio recorded, transcribed, and coded, with several themes emerging.

Themes presented include that the initial cassette discovery involved parental influence, a wide variety of contemporary music genres are listened to via cassette, participants socialize about cassettes both online and via tape trading, some purchases are made due to economical pricing, and that nostalgic feelings were experienced.

This study adds to any existing knowledge on current cassette tape use by this young adult demographic, further detailing reasons of cassette tapes' recent popularity and possibly assisting in trend forecasts of music formats.

Keywords: cassette, cassette tapes, tapes, millennials, analog media
This project was funded by a MEIEA research grant.

\section{Introduction}

In 2014, Hollywood Records released one of the most popular cassette-based soundtrack albums within the past decade. The tape was a soundtrack for Guardians of the Galaxy, a film which grossed approximately $\$ 773$ million worldwide (Box Office Mojo, n.d.). Dubbed Awesome Mix Vol. 1, the compilation included classic tracks by popular artists of the 1970s and 1980s, including the Jackson 5, David Bowie, The Raspberries, The Runaways, and Marvin Gaye. Another cassette compilation from the film, Cosmic Mix Vol. 1, was released less than a year later with music from artists of similar eras. A second volume of Awesome Mix was released in 2017.

According to Billboard - using data from Nielsen $\mathrm{Mu}-$ sic - these were the top three best selling tapes of 2017, racking up nearly 40,000 sold units (Caulfield 2018); other well-known acts rounded out the aforementioned list, including tapes from Eminem (The Eminem Show), Twenty One Pilots (Blurryface), Kanye West (Yeezus) and Nirvana (Nevermind), plus soundtracks for Stranger Things and Purple Rain, and a Hamilton mixtape. Cassettes have persisted in the underground since its commercial sales downturn in the $1990 \mathrm{~s}$, with several independent labels continuing to release music on the format for limited distribution. However, with support from prominent artists and labels, cassettes - a format considered as obsolete or archaic by some, given always-accessible digital music delivery-had exhibited an unforeseen ability to once again find relevancy in popular culture.

Philips originally introduced the Compact Cassette format in 1963 (Rudser 2011) and it would eventually become a commonplace medium of consumer music playbackplus a commonplace medium for home music recordingthough some record labels were not initially enthused by 
the format's audio reproduction quality (Drew 2014). The Sony Walkman was introduced sixteen years later, providing mass personal portability for the cassette player and aiding to propel the format's popularity (Rudser 2011). By 1986, cassettes overtook other formats (Graham and Hardaker 2003), comprising approximately $63 \%$ of music sales in 1987 (DeBarros 2001). In 1988, reported cassette sales in the United States would reach a peak shipment of 450 million units (Rudser 2011), possibly temporarily assisted by late-1980s major-label return policies that hindered retail sales of the vinyl LP format (McLeod 2005).

By 1990, sales hit a slight downturn at 442 million annual units (Funk 2007), with an increasing presence of the compact disc, which - according to the Recording Industry Association of America (RIAA) - would outsell cassettes two years later (Bair 2007). Near the end of the decade, cassette sales were just over one-third of its peak, at 173 million (Newman 2008). The cassette's decline continued throughout the 2000s, with reported figures of 8.6 million units in 2004 (Beach 2010), 700,000 in 2006 (Funk 2007), 400,000 in 2007 (Newman 2008), and 34,000 in 2009 (Brown 2010). With the advent of file sharing, dedicated MP3 players, and smartphones capable of playing back entire music libraries, physical media - including the cassette tape- - had started to take a back seat to the more prominent, less tangible forms of virtual music distribution.

However, in the current decade, sales of cassette tapes have taken a turn towards popularity again. Far from previous figures registering in the hundreds of millions, the cassette has continued to soldier on in the music marketplace. Reported figures note that by 2014, 50,000 units had sold (Onsgard 2016), increasing to 74,000 in 2015 and 129,000 by 2016 (Caulfield 2017). The most recent tally is 174,000 units sold (Caulfield 2018). A positive sales trend is recognized, finding the cassette in more acceptance by the listening public.

This aforementioned public is split among listener demographics. While Generation X audiences, in age brackets nearing their 40s and above, may be revisiting memories of a dominant format from decades ago (Baldwin 2015) or are persisting in playing a format that was never relinquished from their collections, a younger audience segment - in particular, millennials - is also taking to the cassette as a newly-preferred format, with reports of consumers purchasing new cassettes in age groups ranging from teenagers to those in their thirties (Sessa 2011). While definitions of millennials' birth years vary-generally between the mid-1980s to early 2000 s - this cohort features a wide variance in experiences. Some may have not been exposed to cassettes until recently; others are longtime users. While tagged as a "digital generation" (American Press Institute 2015) or "digital natives" (Pew Research Center 2014), certain mil- lennials are taking interest in the past's analog ways. Dowling (2017) noted that, "to millennials, it seems, the cassette represents something between music and artifact" (para. 2 ). It is of interest to examine this cohort, to better understand their experiences of interacting with cassettes, both as consumers with purchase experiences, and as listening audiences in playback experiences, given their investments in digital platforms. The juxtaposition of the vintage and analog, amid such forward-thinking technology-such as subscription-based streamed playlists - is what makes this a compelling demographic of study for cassette use.

\section{Literature Review}

The cassette's popularity decline-coinciding with advancements in and increased audience adoption of digital audio playback technologies - was noted in the press. DeBarros (2001) said that the cassette was "close to being fast-forwarded into the technological graveyard" (para. 4). A chief executive officer of a cassette duplication company was quoted by Brown (2010) stating that "[cassettes are] a novelty, and it will die down" (para. 11). The Oxford Concise dictionary eventually removed the term "cassette player," and Sony was reported as ending its cassette Walkman shipments in 2011 (Rudser 2011; Onsgard 2016). Tape player sales peaked at 18 million in 1994, and were down to 480,000 by 2007 (Newman 2008). The last new vehicle available in the United States with a factory-installed cassette player was the 2010 Lexus SC 430 (Williams 2011).

However, much was also reported on the re-emergence of the cassette over the past decade, including speculation on why the format found recent spikes in popularity. Discussions include that some audiences are seeking a tangible medium, missing the interaction with recorded music not found in clicking on files stored in digital devices. Tape label operator Michael McGregor in Parish (2010) notes that the "music-consuming public is probably a little bored with MP3s, especially a decade after the iPod rose to prominence" (para. 20). There is also the economics behind the production of a cassette, in that it is cheaper to replicate than other, more popular physical formats such as $\mathrm{CD}$ and vinyl, and in turn making it less expensive to sell at an average of $\$ 5$ to $\$ 6$ per unit for an independent release (Galiba 2017; Quin 2016; Markicevic 2016; Rudser 2011; Sessa 2011). A recent report estimates the approximate replication cost for 150 tapes at $\$ 100$ (Ratzlaff 2015). Furthermore, the inexpensive nature of the cassette allows for an easier point of entry for collecting physical recordings (Grobaty 2016), especially for listeners who did not have an opportunity, given retail prices of new compact discs and vinyl records.

An additional point of consideration in the cassette's re-emergence is the embrace it has received via major retailers. Fashion sellers such as Urban Outfitters, technolo- 
gy retailer Best Buy, and online superstore Amazon have recently sold cassettes and cassette players (Chapman 2015); in fact, Urban Outfitters sold $21 \%$ of total U.S. cassette sales in 2016 (Caulfield 2017). Cassettes are no longer relegated primarily to underground or independent music scenes, with certain major label artists issuing new releases on tape. Additional evidence of the format's recent visibility are cassette-related events such as the annual International Cassette Store Day, which started in 2013 (Quin 2016), a segment on NBC's Today Show regarding the cassette's return, the "Top Tape" Cassette DJing night in Los Angeles (Martins 2011), or even items such as cassette-imaged cell phone cases and cassette coffee table designs (Anderson 2017).

Still, it is also important to note the relevance to the examined demographic. Millennials have been the primary user cohort on Spotify, comprising nearly three-fourths of weekly streaming activity from the service (McIntyre 2016), so their foothold of usage in the digital domain of music delivery is well established. However, nostalgia appears to have lent a hand in the revival of the cassette, and those under thirty years old may be enticed by the sheer novelty of the medium (Galiba 2017). There are also the manual components of operation, which requires patience in waiting for the cassette player to conduct its routine operations, such as rewind or fast forward (Olivarez-Giles 2017; Allen 2006). As stated in Farrell (2017): "In many ways, it's the generation raised on an everything-digital media diet that's heralding the revival of the tangible... Some recent studies have shown that 20 -somethings prefer reading books on paper instead of on tablets... The medium can be as valuable as the media itself" (para. 6).

\section{Research Questions}

Based on the review of literature and the aims of this exploratory qualitative study, three research questions are presented:

- RQ1: What are the cassette tape purchase experiences of millennials?

- RQ2: What are the cassette tape playing experiences of millennials?

- RQ3: Why do millennials prefer to use cassette tapes in addition to, or instead of, other forms of music media?

\section{Methodology}

This study incorporates a qualitative exploratory framework. In-depth, semi-structured interviews were conducted with eighteen qualifying participants from February 2018 to June 2018. This sample population figure falls within general qualitative interview population guidelines for phenomenology (Brinkmann 2013; Creswell 2013). Interviews were conducted both in-person and via phone. Most participants were recruited from in-class announcements and mass emails sent to students at a large university in the western United States; most interviews were conducted in person on the university campus. Additional participants were recruited via public social media postings on music-oriented online forums; these participant interviews were conducted via phone and all participants were U.S.-based. Commencement of the study was approved per the Institutional Review Board (IRB).

Prospective participants were required to meet a few prescribed qualifications. To fit a general definition of "millennial"- closely aligned to the 1982-2000 range used by the U.S. Census Bureau (United States Census Bureau 2015) and be included as part of the cohort under examination, participant birth years must have been between 1983 to 1999. Also, all participants must have been at least eighteen years of age at the time of the interview. To ensure that experiences were recent - therefore current to cassette usage trends and fresh in memory of such usage and purchaseseach participant must have purchased and played a cassette tape sometime within the previous two years. Furthermore, in accordance with IRB protocol, participants were required to review, sign, and return an informed consent document prior to the interview.

An interviewer's guide was generated to establish a baseline of questioning among the purposefully selected participants. One pilot interview was conducted to ensure that questions were appropriate for the study. All interviews were recorded via a digital audio recorder. The average interview length was 21 minutes. Each interview was transcribed and reviewed via Microsoft Word documents of the transcriptions. The data review process entailed both memoing and categorization of responses, similar to that of grounded theory's methodology (Corbin and Strauss 2008; Creswell 2013).

\section{Results}

Eight primary themes and twelve secondary themes were formed from the responses, as noted in Table 1. The first primary theme emerging from the data was initial discovery. Questions regarding earliest memories of cassette tapes elicited many anecdotes from participants, chiefly that the initial discovery of the cassette was largely due to their parents' use of the format, giving rise to a secondary theme of parental influence. Although some participants had used cassettes as youngsters (elementary school-aged), several did not interact with cassettes until well into their teenaged years. A majority of the participants shared accounts of their youth and upbringing tied to a parental influence. 


\begin{tabular}{|c|c|}
\hline \multicolumn{2}{|c|}{ Themes from Responses } \\
\hline Primary Theme & $\begin{array}{l}\text { Secondary Theme(s) } \\
\text { (if applicable) }\end{array}$ \\
\hline 1. Initial Discovery & Parental Influence \\
\hline 2. Purchase Experience & $\begin{array}{l}\text { Initial Cassette Purchases } \\
\text { Purchase Location }\end{array}$ \\
\hline 3. Purchase Motivation & $\begin{array}{l}\text { Economical Cost } \\
\text { Preview Opportunities }\end{array}$ \\
\hline 4. Cassette Format Preference & $\begin{array}{l}\text { Sonic Quality } \\
\text { Cassette Characteristics } \\
\text { Cassette Design }\end{array}$ \\
\hline \multicolumn{2}{|l|}{ 5. Playback Operation } \\
\hline \multicolumn{2}{|l|}{ 6. Music Genres } \\
\hline 7. Cassette Socialization & $\begin{array}{l}\text { Social Media Interactions } \\
\text { Tape Trading }\end{array}$ \\
\hline 8. Uniqueness & $\begin{array}{l}\text { Nostalgia } \\
\text { Sequential Listening }\end{array}$ \\
\hline
\end{tabular}

Table 1. Themes from responses.

Some participants noted that they had played - or their parents had played for them-age-appropriate material on cassettes, including this recollection: "I think earliest memories would have to be probably when I was a toddler, my parents had cassette tapes. Sometimes they'd put songs, like little kids' songs, off of boombox cassettes."

Another participant shared a similar account: "I think probably my earliest memory would have to be when I was little, my mom would play us stories off of cassette tapes. Stories meant for children with recorded voices, audio books, but I don't know if they had a specific textual reference... Stories about animals I think, but it was a long time ago, but yeah, that was probably my first experience with a cassette tape. I think that was around when I was maybe four, so that would've been 2002."

Recollections were even shared in regard to which exact locations - specifically in vehicles - they remember listening to cassettes as young children, including one from this participant: "When I was born, [my father] had them around the house, and I remember sitting in his Honda Civic, listening to Simon \& Garfunkel as a kid." A second participant had a similar reflection in regard to parental influence and their vehicle, stating, "I don't know, really, when I learned about them, but as a child they were around in the old pickup truck. The first tape of my parents' that I remember is Dwight Yoakam's Guitars, Cadillacs, Etc., Etc. And, I remember listening to that tape over and over on repeat."

The operation of the parents' home audio system and the opportunity to use it for recording purposes was also a component of the initial discovery of cassette usage. "I was really young, seven or eight," said one participant. "My mom and I had moved into our apartment, and she had a really big speaker system that had a cassette tape thing. We had these blank cassette tapes that you could record onto. So I was trying to be like a DJ. You could record from the radio. I would hit record and then change the radio station and hit record again, and it would be a mix of a bunch of random little clips of songs."

Another participant also noted an early ability to operate a cassette player, as owned by their father - eventually they would receive a cassette recorder of their own as a toddler:

From the time that I was in a walker, my parents would tell me that I wouldn't leave my dad's stereo alone. It's like they had to turn it up against the wall because I was constantly trying to put tapes in it, or turn it on or something like that. I grew up with it...I would say the first, like, actual tape player, or recorder that I ever got, I was probably about two or three. So, 1992-93, give or take maybe. It was one of those Fisher-Price things. Like if I could remember the first time that I ever had one that I could use on my own, that would be it.

The purchase experience primary theme discloses ways in which millennials acquired their cassette tapes and includes two secondary themes: initial cassette purchases and purchase locations. The earliest memories of purchasing cassettes are encompassed by the theme of initial cassette purchases. More variance was noted in these answers, as some purchased cassettes several years ago, while others only recently began purchasing cassettes, within the past couple years. Many who recently started purchasing cassettes were well into their high school or college-aged years. Given the broad cohort, such ages correspond to a variance in actual calendar years. The majority initiated their own cassette purchases approximately three to four years ago (2014-2015). Stated one participant, "I didn't really buy my first tape until, I want to say the second year of college... That was, I want to say 2015,2016 or so. I bought a couple of them." Another participant noted, "When I started making money, I think I bought my first cassette....and I think that was in 2016."

Some participants who only recently started purchasing cassettes did so because of the availability to play cassettes in their cars, as noted by this response: "Fairly recently, actually. 'Cause I mean, I hadn't ever had any way to really play them, 'cause I didn't wanna dig through my parents' stuff...They had a stereo, radio, cassette all-in-one that I could have used...I ended up just, once I started driving, just it was easier to use my car than to go out, get the player, bring it into my room, use it that way. Versus, alright I have a car, if I'm driving just pop one in, I'm good to go."

Ownership of a car with a cassette deck as an impetus to 
buy tapes was also found in this response: "I actually didn't make a first purchase of tapes until I got my first car. It was a '96 [model year] so it had a cassette tape [player] inside of it. So that was last March, a year ago...I was too young to be interested in tapes when they were popular but when I was into music there was CDs. When I got my car, it had a cassette tape [player] so I was kinda like, 'Hey, that's cool, I can put a cassette tape into this.",

Other reasons for initial cassette purchases included recently acquiring a player via a friend or family member. One participant noted that it was a boyfriend who had introduced the idea of playing cassettes via a cassette player as a birthday gift. Another participant said that a grandparent assisted in initial cassette purchases - though not without a little inspiration from some popular films: "Well, originally I got my cassette player from my grandpa when I was in Europe this past summer. I think it was also 'cause I watch things like Baby Driver, and I was like, 'Oh, now I have a cassette player.' I think it's kind of cool to have that. And also films like Guardians of the Galaxy where they use a cassette, too."

The purchase locations subcategory includes both new and used purchases made online, at live concerts (often from the artist's merchandise booth), or in physical stores (record stores, vintage/thrift stores, and clothing/lifestyle retailers). One of these clothing/lifestyle retailers was Urban Outfitters, of which a few participants had mentioned. "I started seeing some articles or getting emails from Urban Outfitters showing a throwback section of cassettes, records, and cassette players, like old players with a modern twist...so it was just fun to see, going into a store...because I thought I'd probably not see that again," said one participant.

Record stores were also highlighted by participants' responses, including some who stressed the opportunity to support local and independent retailers, as opposed to larger, nationally-known stores, as stated here: "So as far as purchasing cassettes, I try my very best to try to purchase them in actual stores. I like to support local businesses a lot, and I work for one myself." Another participant also made purchases from brick-and-mortar record retailers, though the original purchase intention was more for vinyl records than cassettes. Nevertheless, it is an interesting point about serendipitous discoveries:

Physical stores, usually, just record stores...I buy vinyl more than I buy cassette tapes, so while I'm there looking at records, then I will usually go over and look at whatever other cassettes they have to offer...I just think it's fun and cool, like when I'm in the store. Most recently I bought an R.E.M. album, and I love the song, 'Shiny Happy People,' and it was that album, and so when I saw R.E.M. and I pulled it out, and I realized that it was that album that had 'Shiny Happy People,' I was stoked. And so, I mean, just like that satisfaction of finding it in the store, and then it's only, like I said, two dollars, and so it's just kind of fun.

A third physical store type mentioned was the thrift or vintage store. Often a haven for discarded or donated goods, it was another location for unplanned cassette finds, as mentioned by this participant: "I'm just a natural kind of junk collector. Anything, like cool trash or whatever. So, one man's trash is another man's treasure. So, we're always digging, just naturally, you know what I mean? The thrift stores, garage sales, and anywhere you can find...a box of tapes on the side of the road, or whatever."

Shopping at thrift and vintage stores brought back memories for certain finds, including this brief recollection: "If I was with friends, we'd look through them and have these moments of 'remember this?' or 'remember this person?" Thrift stores and other second-hand retailers were some participants' best options, including this response, due to the distance from record retailers: "Most of the tapes that I get come from thrift stores, flea markets. Every great once in a while-I mean we don't really have any record stores around here - but, I mean just within the past month I was at a record store and I did buy a couple of tapes there."

Online outlets were also used as purchase locations by participants, primarily via websites linked directly to the artists themselves (such as Bandcamp), or via the record label releasing the artists' cassettes. This participant was cognizant of the royalties paid to the artist and wanted to ensure the artist would receive maximum benefit from the purchase: "I've only ever bought them online...I usually buy my music and cassettes through the artists' page themselves...so that they get most of the [profits]."

A second participant also expressed similar reasons: "I also think that, at least for me, it's a good way to support the artist. If there's an artist that I really like, I will sometimes try to pay for their music either on Bandcamp or something like that. Cassettes are another way of making sure that the money is actually going to them, as opposed to maybe something like streaming their music where they're getting some money, but nothing near as much as actually purchasing the albums...You don't know how much of that actually ends up going into their pockets and obviously streaming, they're getting pennies from."

This participant preferred online cassette purchases via Bandcamp, due to the opportunity to listen to the recording prior to purchase:

Online, it's primarily through Bandcamp. But yeah, everywhere. I just bought three today from a re- 
cord label's online store...Usually, if it's an artist I like, or they're related to an artist I like, one advantage of Bandcamp is, usually, they all have digital, there's a digital aspect to it. So you can listen to it first. So I can preview the album and see if it's something I like. If it's something I like, I'll go ahead and purchase it. And of course, price, there are some artists recently, that are trying to charge $\$ 20$ for a tape, which I feel is ridiculous. Because I know how cheap they are to produce.

Another reason for online purchases is due to the rarity of finding certain artists' cassettes for sale at a local retailer, as noted by this participant: "When it's a new cassette, like the one I wanna buy, it has to be online, because you can't find them nearby. Especially if it's a band that's from out of the country, like this one that I want."

The purchase motivation primary theme developed two subcategories, economical cost and preview opportunities. Some participants said they purchased cassettes due to the economical cost of cassettes, that they had already familiarized themselves with the cassettes' contents - and hence had a preview opportunity - in another medium, and that there was no original intention to purchase cassettes, but rather were spontaneously decided. In terms of economical cost, most noted prices paid for used cassettes ranged from $\$ 0.25$ to $\$ 5$, and new cassettes were approximately $\$ 5$ to $\$ 15$. As for what price ceiling should be placed on new cassettes, the range given was \$15-25.

Participants had made price comparisons between cassettes and vinyl LPs, including this response: "Vinyl's great and all, but that's expensive. It's really expensive. And there's a lot of cult value behind that...[Tape] is more accessible, it's easier to get, it's cheaper, cost effective, and I think that makes it a lot easier for consumers and audiences to give it a try because you're more willing to take the gamble...you can drop five bucks on a tape."

Another participant also noted pricing: "Just depends on what I find for a good price that I have determined. Like, just recently...I got... a local punk band from the 80s. Saw on their website that they had their first album...for eight bucks on cassette. And I'm like, that's a pretty solid price, free shipping, eight bucks, let's go."

Spotify, Bandcamp and social media were all preview opportunities for participants to hear the cassettes' contents prior to purchase. This reduced the fear of the unknown, making them more likely to purchase the cassette.

Sentiments of familiarity and an ability to preview the cassettes' contents were echoed by this participant: "The unique thing about the Awesome Mixes from Guardians of the Galaxy, it's all music that was out in the 70s and 80 s, so I've heard it a million times on the radio, on Spotify, on my own phone...so it's all music that you've heard before, and it's like famous music, but it's just on one cassette tape." Even if the music was not made previously famous, a chance to hear songs online - regardless of their success - from the artist's social media page or via another person, was noted here: "When you purchase from an artist [on Bandcamp], they alert you anytime the same artist will put out new music...Then social media, I'm primarily on Instagram, so I see new music coming out on there. And then from friends. I have friends that are also interested in similar types music that also collect cassettes, and they'll let me know about new releases, if it's something that I've missed."

The next primary theme, cassette format preference, examined why participants opted for cassettes when other music media was readily available. This theme included two subcategories, sonic quality and cassette characteristics. Many found that the cassette tape had a unique sonic quality that differentiated it from digital formats - including listening to music via a smartphone - though some had also made sonic comparisons to vinyl records. One participant stated that cassettes were "not as sharp" as when listening to music via the phone and provide a more "nostalgic feel." Another spoke of its "better quality sound for the song" and that the experience was better than using the phone for playback.

The descriptors of "warm" and "very smooth" were mentioned by another participant, who also stated, "it's not as scratchy as a vinyl record." The vinyl record was also compared to cassette from a different participant: "The tape, like vinyl, it still re-creates some frequencies that you can feel...I saw this band live and then played their tape, and I could feel the bass and I could feel things that I've never heard before. I've listened to this [album] on MP3, WAV and different formats, but it wasn't until I listened to it on tape that I got this experience...it retains the integrity of the original recordings."

Others had pointed out the audible artifacts in the playback of the cassette as a sonic quality preference: "In vinyl and tapes, there's a bit of a hiss and crackle. There's a difference in like, the color of the audio being played, and honestly, I really like that, I value that because it's something different and there's something oddly charming about it, compared to listening to an MP3." In fact, the mechanical noise of the player itself was mentioned here as a sonic quality: "I kind of like the winding kind of sound. I also like the clicking when it reverses and things like that. Just like that feeling that's physical."

The cassette format preference theme also sprouted a subcategory of cassette design, in which participants mentioned the cassette relative to its inherent size or operational characteristics. "Like [for] a CD, you just press play and it'll be fine, but a cassette you have to flip the tape, you have to make sure the tape doesn't get eaten up, things like that. 
You have to start beginning to end or you are going to be meticulously rewinding, fast forwarding, if you are trying to find a certain spot of the song, things like that... If you have a tape that you want to start from the beginning, but you just finished playing the side, you've got to rewind it."

Another cassette design comment regarding its operation was offered by this participant who stated: "Tapes are a much quicker process. Put it in the tape deck, press play, it goes. With vinyl, you have to flip sides. So usually, it's easier to put a tape on. And since I have a...dual tape deck, I can put two tapes in, and they'll just play continuously. So I can put two tapes in and go about and do stuff around my house while I'm listening to music without having to come and flip a record over every 10 minutes, or 15 minutes, or so."

The cassette's physical size and footprint, another aspect of cassette design, was a preferential factor for this participant: "For me, I've always found cassettes to be awesome, being that they're minimalistic and then they don't take up as much space, and they also look really wonderful on your wall as well...It can be just as impressive as records." And the physical construction and sturdiness of the format was mentioned in this response:

I love tapes because they're so durable. Even though they can shatter and fall apart, you can pretty much put them back together. As long as you keep them out of the sun, and you take care of them, they'll last a lifetime. I have 40-year-old tapes, easy, in our collection. You know, just take care of the things that you like, put it back in business. They hold up better than CDs in our lifestyle. You toss them around, and they still sound good, really. CDs, you toss them around, and before you know it, they're skipping and they're not gonna want to play anymore.

In terms of the next primary theme, the playback operation of cassettes, most participants had either used a portable player or component stereo tape deck in their residences - or if in the car, used the vehicle's cassette player. For those playing cassettes at home, the types of players ranged from vintage to current, from portable to nearly permanent. One participant shared that their player-which was pulled from storage and was initially acquired at a young agestill worked perfectly. Not all cassette players were individual items; some were integrated into systems featuring other playback options, including CD players, auxiliary inputs, Bluetooth streaming, and turntables.

This participant had a more unusual cassette player, which apparently was not originally intended for home use: "I tend to stick with my one player, which is my Sony. It is a single deck with a built in speaker. And it does have a built in mi- crophone that is connected to it...It's a much older model. It was more for teaching, rather than listening and stuff like that...There's this four-headphone port that you can connect to it, so that way that all those students could be able to hear the same cassette."

Some owned more than one cassette player, in either portable or home stereo forms, as detailed by this participant's response: "I have some small, I have a Walkman, and I have another little small personal stereo. But primarily, in my study, I have a Marantz receiver and an Onkyo dual cassette player. They're connected to two big sets of speakers from the $80 \mathrm{~s}$...Let's see, I have a small, let's see, what is this one? It's an Aiwa, A-I-W-A. It's also old. It's from my grandma, actually."

As for listening to cassettes in the car, responses noted that some vehicles were hand-me-downs, and therefore had already featured cassette decks, largely due to the vehicle's age. Years of participants' vehicles with tape decks - if mentioned-ranged from 1995 to 2004. Some listened to cassettes in the car due to a lack of other audio options in the vehicle: "I listen to cassettes sometimes in my car because I have a Honda, [model year] 2000, and my CD player doesn't work."

For this participant, the car was nearly the only location in which cassette playing occurred:

It's a 1999 Lexus something...The CD [player] is a pain, though, because it's got a whole slot that you have to pop out. It has I think five or six slots that you'd put the CDs in. Yeah, so I have to take that, pop it in, pop it out if I wanna take like a single CD out. And like, I've been listening to this one for a while, gotta take it out. Oh, it's a hassle. So that's why cassettes - because it's in the center consoleit's a lot easier. So that's why I even take it over CDs...I think I keep probably 15 [cassettes] that I just keep in the center console.

A better understanding of the types of music being played via cassette gave rise to the music genres primary theme. Participants were split between acquiring used cassettes from artists of the $60 \mathrm{~s}-90 \mathrm{~s}$ - some of whom stated originally hailed from their parents' collections - and contemporary artists of the 2000s and current decade. Of the more classic music genres, the range of styles was eclectic and included rock, Motown, contemporary Christian and funk. This participant noted a particular filmmaker, made popular via successful 1980s movies, as an influence in their selection of cassettes: "Mostly, I wanna say I have a lot of, probably $80 \mathrm{~s}$ is the one that I have the most...'cause I watched a lot of John Hughes movies as a kid." Another participant highlighted the variance of classic genres in their tape collec- 
tion, stating, "It's a huge mix from oldies like Beach Boys type stuff, all the way to country and rap or hip-hop groups. And the hip-hop groups would mainly be 90s."

In terms of more recent music genres, participants' cassettes also featured a spectrum of artists and sounds, including surf punk, garage rock, alternative, indie, chiptune, electronic, and hip-hop. Two different participants discussed two subgenres of hip-hop in detail. The first participant noted lo-fi hip-hop artists, plus modern electronic club producers, as regular, current users of the cassette tape format.

Lo-fi hip-hop, I got into online, so through SoundCloud and friends recommending it to me. Since getting into it, a lot of the artists that I will listen to on SoundCloud, they will post that they're releasing their album available for cassette and if I go to a lo-fi hip-hop concert, there will usually be vendors there selling cassettes either of older artists... Then aside from that, modern electronic club music interestingly. It's definitely less common than it is in lo-fi and yeah, lo-fi is definitely the genre where I've seen it be the most dominant trend. A bunch of producers that I follow that make club music actually do release cassettes...it's a weird trend. I've seen maybe five or six of them host daytime dance parties where they'll be releasing a new album and that album is primarily available on cassette. They'll post it online maybe the day afterwards, but there's this exclusivity of if you go to the party, you can hang out with them, buy the cassette, and that more physical material, in-person relationship, as opposed to someone who you only follow online, have never met, and then listen and stream their music. Those are the two genres where I've really noticed it. Even just in the last year almost really picking up...Just a lot of the lo-fi hip-hop producers that I listen to are releasing cassettes through this one label, and if you go on the label's page, they have 100 cassettes available, all pretty underground contemporary, the lo-fi hip-hop producers.

Instrumental hip-hop was another subgenre noted for its use of cassettes: "The type of music I listen to, I listen primarily, on cassette at least, it tends to be instrumental hiphop releases or independent hip-hop artists. And that's what a lot of those artists do as a physical product, because it's cheaper to produce than vinyl. I think it has more appeal aesthetically, than a CD does."

The primary theme of cassette socialization yielded two secondary themes, including social media interactions and tape trading. Participants who shared their cassette playing and purchase experiences with others were the core of the cassette socialization theme. Some spoke of their experiences of social media interactions regarding cassette tapes, including this example of recent purchases: "I do talk about it online, but it's not like I have a dedicated social media site about tapes. I will post up my current purchases on Instagram sometimes, if I'm really excited about them, I'll do that." And this participant noted the use of Facebook to connect with other cassette tape users, stating, "There's a forum that I'm in as well on Facebook, I don't do as much anymore, but people will start sharing their finds and tapes and stuff. If they release music, they'll post it up there and they'll say, 'I have tapes coming up in this next show. If you guys want to come support, I'll have merch.",

Sharing music with friends or family was central to the tape trading subcategory, which exhibited ways in which participants enhanced cassette ownership experiences. As to why one participant engaged in tape trading, they responded: "You give it to someone or let someone borrow it, so they can get into that music or be introduced to something...It's like a gift in a sense, but it's more memorable." The tape trading even crossed state lines, in which this participant traded cassettes via the U.S. Mail: "My best friend also has [cassettes]... she lives in Washington now, she used to live here, so like, we mail [cassettes] to each other and we let each other borrow stuff." Some tape trading occurred with family members, as one participant noted trading tapes with a great-grandparent.

This participant utilized cassettes for both playback and recording, taping music and other audio to cassette, for the purposes of tape trading with others: "We have local scenes where the easiest thing to do is to make tapes. We trade 'em, we like the physical aspect of it. We don't even buy 'em, most of the time we just kinda trade them when we have them. It's just a really cool commodity to share between friends and between local scenes, and getting people's music out there...the social aspect does come with the trading."

The uniqueness of cassette ownership and operation, the final primary theme, was discussed in the interviews, likely due to the rarity of current cassette use - in particular focusing on two unique characteristics (and secondary themes): the nostalgia from cassette use and ownership, and a tendency to engage in sequential listening, rather than skipping tracks within tape releases. While some participants were only recently introduced to the format and had no previous interaction with it in its heyday of the $80 \mathrm{~s}$ and $90 \mathrm{~s}$, a majority of participants said cassettes provide a sense of nostalgia: "Part of it is a romanticization of the past, there's a nostalgia that although people my age didn't experience, or I didn't experience, you still kind of lean on it...it's like looking back at that golden age, and maybe it wasn't that way back then, but it's looked at with that lens." 
A second opinion on the nostalgia of cassettes in current times was shared: "I feel like especially with our generation, people really attach to cassette tapes because they remember growing up with it, especially with the kiddie ones, the kiddie cassette tapes and maybe even have their own little Walkmans - or other ones that are rip-offs of Walkmans - that they had to listen to cassettes before CDs became a really big thing."

This participant provided an added perspective on nostalgia and cassettes:

I think nostalgia definitely plays a big role...Also I think that the kinds of music that I know is popularly released on cassettes, the aesthetics of that music are really tied to that feeling of nostalgia. I guess maybe, I don't know if I would necessarily call it value, but part of maybe the meaning that I derive from it is the connection to that nostalgic aesthetic...Just having a physical object I think is something that's really powerful and obviously is gradually getting diminished in how we listen to music.

The participant who had earlier cited John Hughes as a reason for selecting certain music genres on cassette provided this anecdote on a previous memory:

Going back to the John Hughes movies, I remember there are all these scenes where someone's popping in a cassette, and it's like, I remember being small and looking at thinking, 'One day I'm gonna be old and I'm gonna have my own cassettes to put in my car'... Sometimes you forget how far you've come, and just something as simple as putting in a cassette, for me, I think again, of when I was small and thinking, 'Oh man, one day, I'm gonna be old and I'm gonna be using my own cassette,' so even though it's outdated, to me I still think back to younger me, of having that idea of myself doing something that I, I guess independence or something.

Still, there were responses in which nostalgia did not play a central role in current cassette ownership. For some, it was due to having scant memory of cassette use at an earlier stage of their lives: "I don't remember my parents playing cassettes when I was younger, it was more CDs or records. I don't really feel like cassettes had a lot of meaning from my childhood or anything like that."

And this participant straddled the line of nostalgia, with having an opportunity to feel like they were in the 90s without having actually participated in cassette use during that decade: "I was talking with my friends about how cool it is that we get to kind of re-live the 90s, since we didn't get to walk around with cassette players much... and re-experience the whole factor of it."

One participant labeled cassette ownership as belonging to a "niche subculture" and another mentioned the sequential listening, a subcategory of uniqueness, in the manner of which cassettes are often played: "Having to keep a pen in your car just to rewind it makes it unique...I think it has to do with the nostalgia and sentiment behind the experience of listening to music rather than putting something on shuffle or being in complete control...Artists have to sit down and plan what song is coming next...because sometimes artists want to take you through a journey while you're going through the record."

Another participant responded in a similar fashion, noting the uniqueness and the same lack of a shuffle capability with cassette usage:

I do specifically, maybe for us millennials, because now, streaming is so huge that, I mean, I get that in the past, cassettes weren't probably a big whoop, because that's what everybody did. But now, it's, you know, very unique to me at least, and I think it's really fun. Yeah, like I said, I was always used to streaming, and I still do stream more often, via Spotify, but I just think it's fun to, it's kind of like a thing to play with almost, I don't know, it's just fun, versus just setting my phone down and having Spotify shuffle, I get to actually like, flip it myself, and fast forward and all that stuff.

In fact, there were several mentions of the cassette as a medium that required a listen of the entire album - or at least some songs in their originally intended order - which seemed to be less common in the playback of other, more technologically advanced formats. The sequential listening subcategory was established for these consistent responses: "When you listen to a tape, you're going to listen to the whole album...you're not going to listen to one song and then pick a different artist. At the same time, it forces you to engage more with it." And, from another participant: "Instead of just skipping around pressing next, next, next, next, next, next, next, next on Spotify, you kind of just put it in there and you just press play and you just leave it alone. Until you have to flip it over, obviously."

The same sequential listening subcategory was also represented in this response:

Yeah, I think it's a unique experience because with streaming or a CD, you can easily skip a song you don't like. If you're playing a cassette tape, it's kinda hard to skip a song because you have to fast forward it and figure out where's the next song. So it 
makes it inconvenient to do that. So when you're listening to a cassette tape, you're just listening to it, the bad songs, the good songs, the songs you don't like and you find joy in the simplicity of it. You just listen to it and I don't know... When you buy a used cassette tape, it's not always at the beginning of the album so it's interesting to pop it in and see where the last person stopped it. And how long it's been stopped there. It's just really fun to think about.

\section{Discussion}

As a whole, the millennial participants were largely passionate and enthused about their recent interactions with cassette tapes. In reviewing the literature and participants' responses, several points can be addressed in referencing the research questions posited. In response to RQ1 (What are the cassette tape purchase experiences of millennials?), it is evident that participants actively seek to purchase cassettes for a variety of reasons. Availability of a cassette player was an important cassette purchase stimulation. The introduction to recent cassette playing - which, for most, was initiated in their earliest years via their parents' use of tapes - also came from friends and family enabling them through gifts of cassette players.

Participants were divided in terms of the acquisition of used versus new cassettes and this division extended to the types of retailers from which the participants had made their purchases - some were bought from second-hand vendors, while others were from record stores. Some mentioned cassette purchases made directly from the artist, whether in-person at the concert venue from the artist's merchandise booth, or via their artist's online store, like Bandcamp. These direct artist purchases were of particular note, as more than a few participants stated they did so to circumvent the traditional intermediaries (e.g., distributors, retailers) that extract a share of the recording's sale price. This specific line of logic more clearly illustrates a music consumer that is not only savvy about the various mechanisms found within the record retail business, but is consciously aware of financially supporting their favorite artists in the most direct means possible. Following the idea of sidestepping corporate structures, a couple participants noted a preference to purchase tapes from independently owned music retailers, in an effort to support local businesses.

Participants were also divided on how they sought their musical selections via cassette. Unplanned purchases often sprung from spontaneous discoveries, such as happening upon a cassette at a vintage store, especially if pricing was favorable (a few dollars or less) to reduce the financial risk involved in acquiring potentially unfamiliar releases or heavily worn cassettes. Those who previewed the album prior to purchase also minimized risk; oftentimes, this was for a new recording. Because of the often lower entry price point for cassette tapes, and their respective playing devices, this thread of risk reduction in an effort to engage with a physical media option makes sound, economical sense. Cassette pricing is generally less expensive than vinyl, which made for a more attractive proposition.

Addressing RQ2 (What are the cassette tape playing experiences of millennials?), the participants noted devices used, which ranged from portable, Walkman-style units and in-dash car stereos, to component tape decks connected to home stereos. Types of players also had an effect on how cassette music would be shared. A couple participants offered specific makes and models of their tape decks, with some owning more than one cassette playing option. It was of interest to witness a segment of twenty- and thirty-somethings be as eager about using analog music technologies as they could be about cutting-edge, digital devices.

Another tie to RQ2 is the opportunity-or, perhaps, requirement - to listen to an album in its entirety. With the advent of digital listening technology - starting with $\mathrm{CD}$, and into file-based formats - it has become commonplace for users to selectively listen to albums' songs as they wish, but the cassette made sequential listening a near-mandatory experience. This flies in the face of convention for many in this age group, whose familiarity with other formats offer the flexibility to be discerning with track selection during playback.

In reference to RQ3 (Why do millennials prefer to use cassette tapes in addition to, or instead of, other forms of music media?), some participants stated the cassette had an audio characteristic that was unlike other formats that they have interacted with. For a listener who frequents analog playback, the transition to cassette may not be as noticeable or striking. But because participants were likely to have engaged with cassettes after longtime exposure to playback in a near-exclusive digital environment, the analog qualities of a cassette could appear more unique than say, a transition from CD to MP3, which are both housed within the digital domain. Verbiage used in describing cassettes appeared consistent with descriptors of other analog media, primarily vinyl, with its "warmer" attributes. As for the cassette's design, its compact dimensions and durability were of particular note, as cassette use can include the bulk and weight of a portable cassette player, plus the susceptibility of a cassette to warp or become damaged with exposure to the sun or heat. Furthermore, a tendency for the tape to get caught in the playback mechanism may also call durability into question on occasion.

Rather surprisingly, nostalgia was a consistent theme throughout the interviews. Participants offered many stories regarding cassette play during their childhood. This was of 
note, as the initial expectation was that many millennials may not have regularly interacted with cassettes, or even been exposed to cassettes, early in life due to their ages not entirely corresponding with the cassette's sales peak in the late 1980s. Nevertheless, memories of parents, or even the participants themselves, interacting with cassettes in their more formative years were shared in detail by some.

The number of cassettes in the participants' collection ranged wildly. Some only had a few, while others had in excess of one thousand. The median collection contained about thirty cassettes, though several had fewer than ten. While some participants expressed a desire to start a record collection, and viewed their purchases and acquisitions of cassettes as an easy, economical entry into becoming more of a collector, the collectability of cassettes was not commonly discussed in the interviews.

Approximately one-quarter of the participants interviewed stated that they do not use social media much, if at all. How their minimal usage corresponds to an interest in cassette tapes was not clarified. Participant statements regarding the lack of social media usage include, "I'm not really a social media junkie...I'm not on social media $24 / 7$, I don't like the idea of it much, either." Another participant stated, "I don't really use social media pretty much at all. So, but then again I'm the exception rather than the rule of most of my friends." And a third participant noted, "Yeah, I'm not that avid of a social media poster necessarily. I don't really share that much and definitely I've never shared anything about cassettes on social media." While the proportion of low participation in, or lack of, social media use is still a minority of the participant population, it is noteworthy that certain participants hold meager interest in these popular technological platforms, given that social media use is quite prevalent among the demographic according to the Pew Research Center, which found that $88 \%$ of adults ages 18-29 reported usage of social media (Smith and Anderson 2018).

\section{Limitations and Future Study}

Because of the participants' birth years - which are generally acceptable for the millennial cohort - the range in ages was quite wide. Rather than the typical undergraduate university age set of approximately 18-24 (about 6-7 years' span), the participant population had an age range of early-20s to mid-30s, with estimated age span of 15 years. This created a high degree of variance in responses and memories, as some millennials had used cassettes in their early youth, due to the tape still being a popular medium at that point in time, whereas others had no early interactions or memories. To receive a more focused set of responses, it is advisable to curtail the age range to a narrower span, perhaps more akin to that of the aforementioned undergraduate age set, to better understand the fresh nuances of the cassette tape experience. Also, a study of cassette use among the following cohort, Generation Z (also known as Post-Millennials), might be of interest, given that these individuals were raised in an even more digital media-rich environment.

Other relevant studies for the future include examining the cassette sales experiences of music retailers and record labels, to better understand how their approach to marketing, distributing, and selling the cassette today differs - or is much the same - to that of its peak sales period in the 1980s and 1990s. Another relevant study would be to investigate the experiences of current musicians, who are releasing new recordings via the cassette format, to generate a deeper understanding as to why they are electing to use this format and what the benefits may be to their careers and/or audiences. How might these artists modify their approach to recording, artwork, album sequencing, and self-promotion due to the issuance of their music on cassette? (For instance, are they tracking new recordings direct to analog media?) Lastly, because this study featured only a U.S.-based participant population, it might prove useful to also study the experiences of millennial cassette users (plus cassette-releasing artists and record labels) based in other countries. 


\section{References}

Allen, David. "Please Don't Hiss This Ode to Cassette Tapes." Inland Valley Daily Bulletin, July 1, 2006. https://search.proquest.com/docview/379332854?accountid $=9840$.

American Press Institute. "How Millennials Get News: Inside the Habits of America's First Digital Generation." Last modified March 16, 2015. https://www.americanpressinstitute.org/publications/reports/survey-research/ millennials-news/.

Anderson, Patrick. "USF Graduate Rewinds Time." Argus Leader, March 11, 2017. https://search.proquest.com/ docview/1876028820? accountid=40706.

Bair, Jessica. 2007. "Tale of Cassette Tape Winds Down." Central Penn Business Journal, December 7, 2007. https://search.proquest.com/docview/236260127?accountid $=9840$.

Baldwin, Rosecrans. "Our Misplaced Nostalgia for Cassette Tapes." New York Times, December 23, 2015. http://www.nytimes.com/2015/12/24/opinion/ our-misplaced-nostalgia-for-cassettetapes.html?partner=Bloomberg.

Beach, Randall. "Cassette Tapes Hold Fond Memories, Romance for Baby Boomer." New Haven Register, May 14, 2010. https://search.proquest.com/ docview/243038411?accountid=9840.

Box Office Mojo. "Guardians of the Galaxy." Accessed June 14, 2018. http://www.boxofficemojo.com/movies/?id=marvel2014a.htm.

Brinkmann, Svend. 2013. Qualitative Interviewing: Understanding Qualitative Research. New York: Oxford University Press, 2013. ProQuest Ebook Central.

Brown, August. "Let's Go to the Tape," Orlando Sentinel, August 10, 2010. https://search.proquest.com/ docview/744358801? accountid=9840.

Caulfield, Keith. "U.S. Cassette Album Sales Increased by $74 \%$ in 2016, Led by 'Guardians' Soundtrack." Billboard, January 20, 2017. https://www.billboard. com/articles/columns/chart-beat/7662572/us-cassettealbum-sales-increase-2016-guardians.

Caulfield, Keith. "U.S. Cassette Album Sales Rose 35\% in 2017, Led by 'Guardians of the Galaxy' Awesome Mix Tapes.” Billboard, January 5, 2018. https://www. billboard.com/articles/columns/chart-beat/8092853/ cassette-album-sales-rising-2017.

Chapman, Shelby. "3 Tips to Starting Your Cassette Tape Collection." Daily Emerald, October 21, 2015. https:// search.proquest.com/docview/1724823989?accoun$\underline{\mathrm{tid}=40706}$.
Corbin, Juliet, and Anselm Strauss. Basics of Qualitative Research (3rd ed.): Techniques and Procedures for Developing Grounded Theory. Thousand Oaks, California: Sage, 2008.

Creswell, John W. Qualitative Inquiry and Research Design: Choosing Among Five Approaches. Thousand Oaks, California: Sage, 2013.

DeBarros, Anthony. "Tangled Up in the Past: As the Future of Music Becomes Increasingly Digital, the Humble Cassette Tape Fights to Retain its Magnetism." USA Today, November 23, 2001. https://search.proquest. com/docview $/ 408914259$ ?accountid $=9840$.

Dowling, Tim. "Could These Old Cassette Tapes be My Cash in the Attic?" The Guardian, November 7, 2017. https://www.theguardian.com/commentisfree/2017/ nov/07/cassette-tapes-attic.

Drew, Rob. "New Technologies and the Business of Music: Lessons from the 1980s Home Taping Hearings." Popular Music \& Society 37, no. 3 (2014): 253-272. https://doi.org/10.1080/03007766.2013.764613.

Farrell, Michael. "Cassette Comeback: For Fans, 'A Yearning for Something You Can Hold." The Christian Science Monitor, May 19, 2017. https://www.csmonitor. com/USA/Society/2017/0519/Cassette-comeback-Forfans-a-yearning-for-something-you-can-hold.

Funk, Josh. "Cassette for Life? Tapes Still Relevant." Journal-Gazette, August 14, 2007. https://search.proquest.com/docview/411433141 ?accountid=9840.

Galiba, Mayeesha. "The YouTube Generation is Listening to...Cassettes?" Boston Globe, May 28, 2017. https:// search.proquest.com/docview/1902819920?accountid=9840.

Graham, Gary, and Glenn Hardaker. "Impact of On-Line Technologies for E-Music Supplier Networks." Journal of Services Research 3, no.1 (April 2003): 5-27.

Grobaty, Tim. "Rewind: Cassette Tapes are Making a Comeback." Press-Telegram, March 10, 2016. https:// search.proquest.com/docview/1772374592?accoun$\underline{\text { tid }=40706 .}$.

Markicevic, Milos. "Return of the Cassette Tape." The Depaulia, February 23, 2016. https://search.proquest. com/docview/1767834250?accountid=40706.

Martins, Chris. "Pop \& Hiss Profile: All Wrapped Up in Cassette Tape." Los Angeles Times, May 3, 2011. https://search.proquest.com/docview/864309087?accountid $=9840$.

McIntyre, Hugh. "Millennials are Leading the Spotify Revolution." Forbes, April 20, 2016. https://www. forbes.com/sites/hughmcintyre/2016/04/20/millennials-are-leading-the-spotify-revolution/\#6ff380ed5b78.

McLeod, Kembrew. "MP3s Are Killing Home Taping: The Rise of Internet Distribution and Its Challenge to 
the Major Label Music Monopoly.” Popular Music \& Society 28, no. 4 (October 2005): 521-531. https://doi. org $/ 10.1080 / 03007760500159062$.

Newman, Andrew Adam. "Say So Long to an Old Companion: Cassette Tapes." New York Times, July 28, 2008. https://www.nytimes.com/2008/07/28/business/ media/28cassette.html.

Olivarez-Giles, Nathan. "Can't Stop the Music: The Cassette Tape May Have Been Given the Heave-Ho Long Ago, But the Format's Nostalgic Appeal is on a Comeback Tour." Wall Street Journal, March 11, 2017. https://search.proquest.com/docview/1875989655?accountid $=9840$.

Onsgard, Kristen. "Cassette Tapes are Trendy Today, But Always Cool." The Depaulia, March 2, 2016. https:// search.proquest.com/docview/1770449308?accountid=40706.

Parish, Matt. "Tale of the Tapes." Boston Globe, July 23, 2010. https://search.proquest.com/ docview/641697446? accountid=9840.

Pew Research Center. "Millennials in Adulthood: Detached From Institutions, Networked With Friends." Last modified March 7, 2014. http://www.pewsocialtrends.org/2014/03/07/millennials-in-adulthood/.

Quin, Kevin. "Pressing Rewind with Cassette Store Day." University Wire, March 4, 2016. https://search.proquest.com/docview/1770439754?accountid=9840.

Ratzlaff, Angela. "Selling New Rock 'N' Roll in an Old-School Format." Orange County Register, May 7, 2015. https://search.proquest.com/ docview/1679319222? accountid=40706.

Rudser, Lauren. "Miss the Hiss? Fanatics Flip for Tunes on Cassette Tapes - Album Connoisseurs Eschew the Shuffle, Embrace Flaws; That 'Sweet Plasticy Smell.", Wall Street Journal, October 20, 2011. https://search. proquest.com/docview/899112400?accountid=40706.

Sessa, Sam. "Rewound \& Revived." The Baltimore Sun, April 17, 2011. https://search.proquest.com/ docview/862616408? accountid=9840.

Smith, Aaron, and Monica Anderson. "Social Media Use in 2018." Pew Research Center. Last modified March 1, 2018. http://www.pewinternet.org/2018/03/01/social-media-use-in-2018/.

United States Census Bureau. "Millennials Outnumber Baby Boomers and Are Far More Diverse, Census Bureau Reports." Last modified June 25, 2015. https:// www.census.gov/newsroom/press-releases/2015/cb15113.html.

Williams, Stephen. "For Car Cassette Decks, Play Time is Over." New York Times, February 4, 2011. https:// www.nytimes.com/2011/02/06/automobiles/06AUDIO.html.
Waleed Rashidi is an assistant professor in the Department of Communications at California State University, Fullerton, and also serves as advisor to the Entertainment and Tourism Club and Comm Week. Rashidi has worked as an editor at Mean Street Magazine and the Inland Empire Weekly. He hosts a jazz radio show at KSPC 88.7 FM, contributed to five books, and has freelanced for the Los Angeles Times-Brand X, Alternative Press, Orange County Register, Modern Drummer, E! Online, and OC Weekly. Rashidi earned his doctorate in education from the University of $\mathrm{La}$ Verne, an MA in communications from CSUF, and a BS in communication-journalism from Cal Poly Pomona. LinkedIn: https://www.linkedin.com/in/waleedrashidi

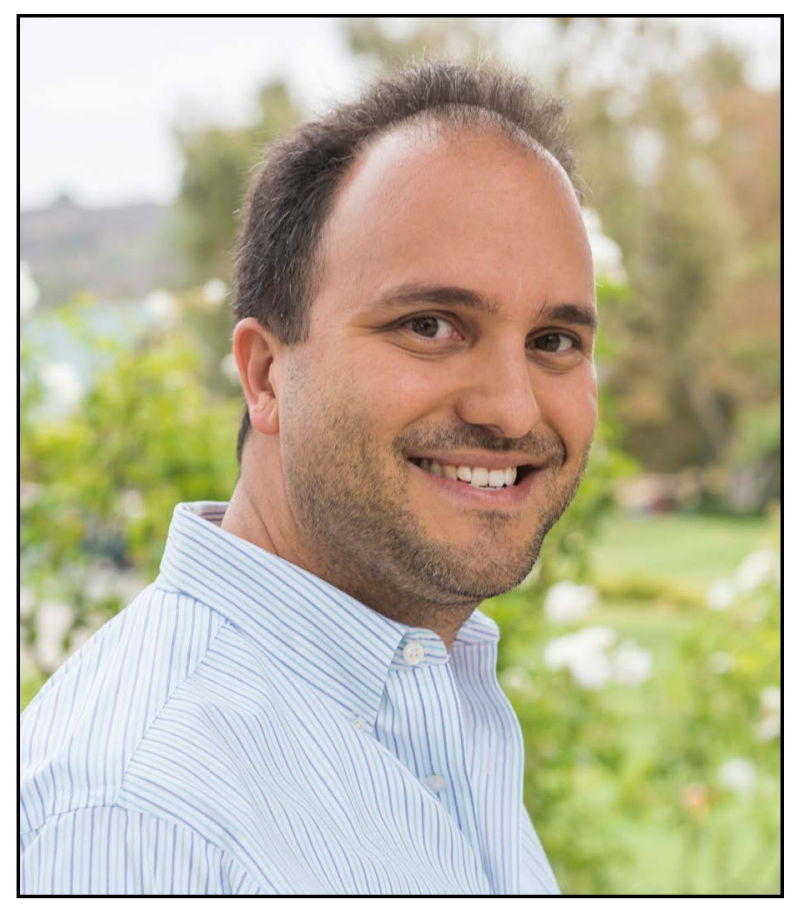




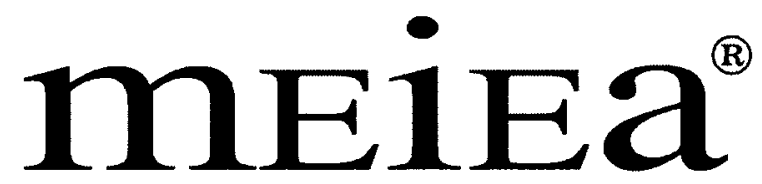

MUSIC \& ENTERTAINMENT INDUSTRY

EDUCATORS ASSOCIATION

\section{PROCEEDINGS OF THE \\ 2018 INTERNATIONAL SUMMIT}

OF THE

\section{MUSIC \& ENTERTAINMENT INDUSTRY EDUCATORS \\ ASSOCIATION}
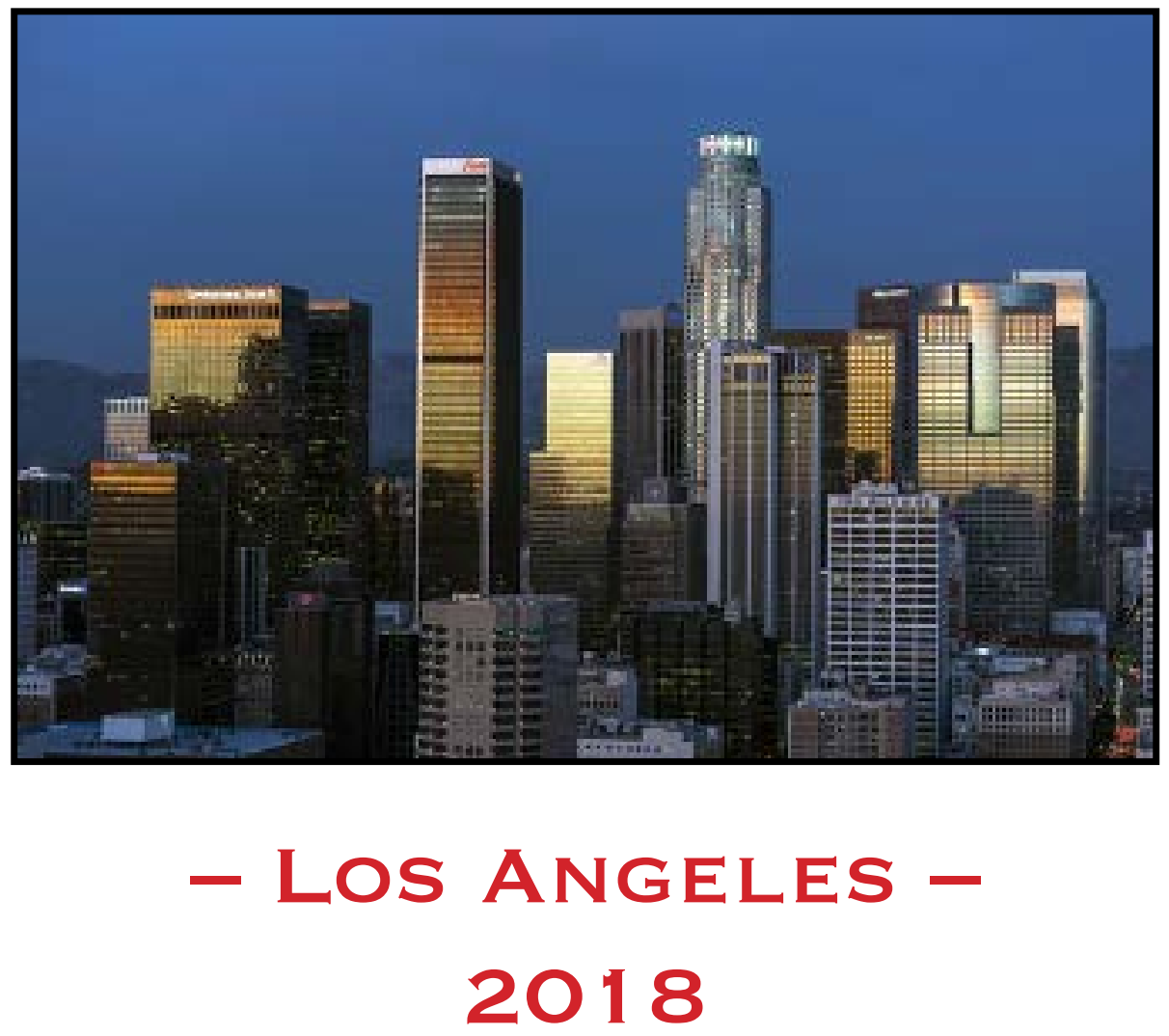

March 22 - 24, $2018 \cdot$ Embassy Suites by Hilton - Los Angeles/Glendale 